\title{
Changes of the Structure Indicators and the Salinity Field Average Value in the Sea of Azov
}

\author{
E. O. Spiridonova ${ }^{1}$, B. N. Panov ${ }^{1,2} \bowtie$ \\ ${ }^{1}$ Kerch State Maritime Technological University (KSMTU), Kerch, Russian Federation \\ ${ }^{2}$ Azov-Black Sea Branch ("AzNIIRKH") of FGBNU "VNIRO", Rostov-on-Don, Russian Federation \\ panov_bn@mail.ru
}

Purpose. The work is aimed at continuing the started in the previous papers investigations of structure of the Azov Sea salinity field based on the oceanographic survey data collected since 2000. Interest in studying this parameter is conditioned by its anomalous increase after 2006.

Methods and Results. The data of 49 seasonal oceanographic surveys carried out in the Sea of Azov by the Azov-Black Sea Branch of "VNIRO" ("AzNIIRKH") from 2001 to 2016 permitted to calculate the following: the radii in the concentration region of the field spatial correlation function in the meridional and zonal directions for the surface and bottom layers (the characteristic of the field homogeneity); the ratio between these radii; the sea-average values of salinity field for the surface and bottom layers. The time graphical and the paired correlation analyses of the calculated indicators' series were done. The average values of the meridional and zonal radii of the concentration region of the spatial correlation function (42.5 and $47.1 \mathrm{~km}$ ) testify presence of two relatively isolated zones in the sea related to the water circulation. These zones are formed under the conditions of the eastern winds dominating in the region. The average values of the above-mentioned radii the near-bottom sea layer were approximately equal, whereas in the surface layer, the average zonal radii exceeded the meridional ones. In spring and summer, the meridional radius in the bottom layer surpassed the zonal one. Longterm variability shows that in the surface layer, the meridional radius values tend to increase, and in the bottom layer, the zonal radius ones - to decrease. These trends demonstrate a change in the nature of water exchange in the sea, namely from predominance of the zonal transport to that of the meridional one.

Conclusions. Since 2006, the changes in the structure of the Azov Sea water salinity field (trends towards decrease of the zonal radii and increase of the meridional ones in the concentration region of the field spatial correlation function) resulted from decrease in the river water inflow and increase of water exchange with the Kerch Strait, and were accompanied by growth of average salinity. Water exchange with the Kerch Strait in the bottom layer was the most active in spring and summer. The anticipatory shift of the field structural characteristics by 1 and 2 years relative to its average values makes it possible to forecast them with a two-year advance time.

Keywords: the Sea of Azov, salinity field, field structure, spatial correlation, tendency, water exchange, salinity

Acknowledgements: the authors are grateful to S.V. Zhukova for her assistance in the research.

For citation: Spiridonova, E.O. and Panov, B.N., 2021. Changes of the Structure Indicators and the Salinity Field Average Value in the Sea of Azov. Physical Oceanography, [e-journal] 28(3), pp. 282-293. doi:10.22449/1573-160X-2021-3-282-293

DOI: $10.22449 / 1573-160 X-2021-3-282-293$

(C) E. O. Spiridonova, B. N. Panov, 2021

(C) Physical Oceanography, 2021

Introduction. Almost for the second decade, the Sea of Azov ecosystem has been in a state of unidirectional transformation caused by an abnormally long and significant increase in the sea water salinity, more pronounced than during the salinity period of the 1970s. [1, p. 14]. After the abnormally low average annual value of sea salinity in 2006 (9.63 \% excluding the Taganrog Bay), a steady increase 
in this characteristic is observed (up to an abnormally high value of $13.99 \%$ in 2016).

With the water salinity increase in 1973-1979, there was a decrease in the primary production of water by $2-3$ times, the total biomass of zooplankton - by 2.5-3.2 times, fish catch of the brackish water complex decreased during this period, while marine fish catch increased [2, p. 164-165]. Anadromous and bottom fish species such as sturgeon, bream, vimbets, shemaya, pike perch, herring, ram and gobies suffered from changes in the sea ecosystem [3, p. 91; 3, p. 102; 4, p. 119121].

In ecosystem assessments of the Sea of Azov state, its average salinity is used as a key characteristic. This indicator is defined as a weighted average of the mean salinity of 13 sea areas. Thus, when calculating the average salinity values of sea waters, the salinity field structure variability is taken into account. The average salinity values for the sea as a whole and for each of the regions separately are related to each other to varying degrees and sometimes have multidirectional trends of changes [5, p. 13-15; 6, p. 68], complicating the field structure analysis and modeling.

Structure of the Sea of Azov salinity field is formed under the influence of the variability of the sea water balance components on interannual and seasonal scales. River runoff is the main component of the sea water balance, which ensures its relatively low salinity. Other balance components are precipitation, evaporation and water exchange with the Black Sea through the Kerch Strait.

As a result of the action of these factors, large-scale, persistent frontal zones are formed in the sea. Small frontal zones periodically appear near the Tonkiy Strait and in the areas of the small rivers' mouths. The central sea area is occupied by a fairly homogeneous water mass, characterized by insignificant intra-annual salinity variability [7, p. 233-234]. The salinity field structure is constantly being transformed by water circulation, including that caused by surge winds [8, p. 220221; 9, p. 58-62].

A number of expeditions of the Southern Scientific Center of the Russian Academy of Sciences in 2005-2007 were devoted to the study of the water salinity frontogenesis in the Sea of Azov. They showed a significant variety of frontogenesis and the dynamics of quantitative estimates [10, p. 10-11, p. 15]. A significant role in the long-term process of salinity change is played by the water content of rivers, anthropogenic withdrawal of river runoff and water exchange in the Kerch Strait [11, p. 63-89; 12, p. 16-17].

Structure of the Sea of Azov salinity field was studied before [13, p. 152-158] based on oceanographic surveys in 1992-2003, during the freshening period. As horizontal structure characteristics of the salinity field, the radii of the concentration region of the spatial correlation function of the field (hereinafter referred to as the radii of the concentration region of the spatial correlation function) in the meridional and zonal directions were used. These characteristics are devoid of the inertial properties of the average values of the sea water salinity and indicate a significant variability in the salinity field structure.

Taking into account the fact that in the last two decades anomalously high and low average annual salinity values of the Azov Sea waters have been observed, it 
seems expedient to continue the studies of its field structure based on the materials of oceanographic surveys carried out after 2000.

Materials and Methods. To calculate the characteristics of the Sea of Azov salinity field, materials of 49 spring (April), summer (July - August) and autumn (October) oceanographic surveys, carried out according to a standard grid (Fig. 1) by the Azov-Black Sea branch of VNIRO ("AzNIIRKH") within 2001-2016 (1,101 stations in total), were used. Three surveys were carried out annually. In the summer of 2001, two surveys were carried out (the July survey data were not taken into account in determining the average annual values and in the correlation analysis). In 2003 and 2016 spring surveys were not carried out, but in determining the average annual salinity values, their absence is partially compensated for by the survey materials carried out in these years additionally in July. The sea survey duration (without the Taganrog Bay) was from 7 to 12 days. Water samples for determining salinity were taken with water bottles from the 1-meter surface and bottom layers. The water salinity was determined by argentometric titration (by chlorine content) with an accuracy of $0.01 \%$ with an expert check of the determination results.

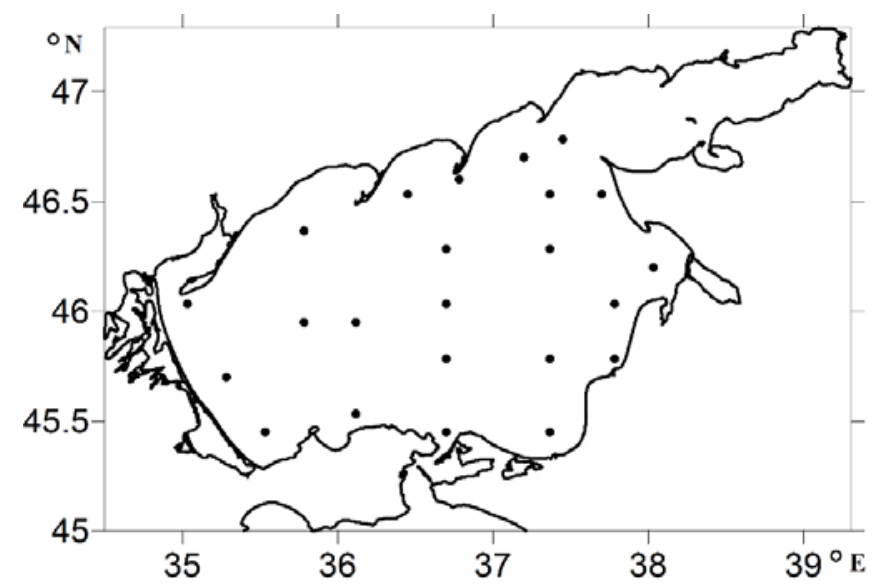

F i g. 1. Scheme of standard stations for oceanographic monitoring of the Sea of Azov used in the "AzNIIRKh" research

The average salinity values of the surface and bottom layers, as well as the total average salinity of the Sea of Azov waters were determined without taking into account the Taganrog Bay according to the generally accepted method recommended in [14, p. 99], taking into account the depth and area of 10 regions.

The radii of the concentration region of the spatial correlation function in the meridional and zonal directions $\left(r_{\text {mer }}, r_{\text {zon }}\right)$ were calculated as characteristics of the horizontal structure of the salinity field according to the survey data for the surface and bottom horizons. In the presence of a constant grid of stations, these statistical characteristics of the field permit to study its uniformity size variability [15]. To determine the radii of the concentration region of the spatial correlation function, the field was optimized, the correlation and structure functions of the 
salinity deviation field were calculated within a $20 \mathrm{~km}$ wide segment of the field moving in the meridional and zonal directions at a distance of up to $150 \mathrm{~km}$. Values of these parameters were chosen based on the average distance between stations and the Sea of Azov size. During the calculations, the methodology and the calculation algorithm recommended in [16, p. 38-51], $r_{\text {mer }}$ and $r_{\text {zon }}$ were determined from the values of the normalized correlation functions calculated for each of the 14 intervals (their number is calculated as follows: $(150: 20) \cdot 2)$ between the calculated points, according to the following formula

$$
r=\sum_{i=1}^{14}\left(\left(\rho_{i+1}-\rho_{i}\right) *\left(\frac{\mu_{i+1}+\mu_{i}}{2}\right) / \max \left|\mu_{i}\right|\right),
$$

where $\rho_{i}$ is the distance between calculated field points; $\mu_{i}$ is the normalized correlation function.

The radii of the concentration region of the spatial correlation function, in contrast to those traditionally used in evaluating the homogeneity of the field of the spatial correlation function radii with a given threshold value, are characteristics that smooth out the variational features of the correlation function. We believe that their application increases the efficiency of the seasonal and long-term variability analysis of field uniformity.

This method and the radii of the concentration region of the spatial correlation function were used earlier in [13]. Therefore, continuing the research begun, the same characteristics of the salinity field structure of the Sea of Azov waters are taken. In addition to the radii of the concentration region of the spatial correlation function, their ratio $r_{\text {mer }} / r_{\text {zon }}$ (hereinafter referred to as the homogeneity index $q$ ) was determined.

Thus, the present paper presents an analysis of changes in the radii of the concentration region of the spatial correlation function $\left(r_{\text {mer. surf }}, r_{\text {zon. surf }}, r_{\text {mer. bottom, }}\right.$ $r_{\text {zon. bottom }}$ ), calculated for the horizons of each survey and the average annual; the radii of the concentration region of the spatial correlation function $\left(r_{\text {mer. mean, }} r_{\text {zon. mean }}\right)$, averages for the entire water column; homogeneity indicators ( $\left.q_{\text {surf }}, q_{\text {bottom }}, q_{\text {mean }}\right)$; indicators of the average salinity of sea waters $\left(S_{\mathrm{A} 3}, S_{\text {surf., }}, S_{\text {bottom }}\right)-$ for each survey and average annual.

The research results. In the period under consideration, the radii of the concentration region of the spatial correlation function in the surveys varied from 16 to $68 \mathrm{~km}$. The $q_{\text {mean }}$ index changed more than three times. No statistically significant relationships were found between changes in $r_{\text {mer }}$ and $r_{\text {zon }}$ (along the horizons and average values for the entire water column).

The depth average values of the meridional and zonal radii (42.5 and $47.1 \mathrm{~km}$ ) are relatively close to each other with some predominance of the zonal component $\left(q_{\text {mean }}=0.93\right)$. These sizes indicate the presence in the sea of two (approximately equal in size) relatively isolated zones associated with the circulation of waters [7, p. 356-358; 9, p. 59], which is formed in the conditions of the prevailing eastern, northeastern and southern winds in the Sea of Azov area [7, p. 62]. This indicates the adequacy of the studied characteristics of the salinity field structure to the processes that form the field. 
Due to the small length of the series of seasonal characteristics under study, their average values (Table 1) have rather wide confidence intervals. Nevertheless, it should be noted that the values of the average zonal radii in the surface layer noticeably exceed the values of the average meridional radii. In the bottom layer, this excess is not large, and the average ratio of the radii in the bottom layer is even slightly greater than 1 .

Table 1

\section{Seasonal values of the radii of the concentration region of the spatial correlation function $\left(r_{\text {mer, }}, r_{\text {zon }}\right)$, $\mathrm{km}$, and the uniformity indicators $(q)$ of the Azov Sea salinity field in 2001-2016}

\begin{tabular}{l|r|r|r}
\hline \multicolumn{1}{c|}{ Indicator } & \multicolumn{1}{c|}{ Spring } & \multicolumn{1}{c}{ Summer } & \multicolumn{1}{c}{ Autumn } \\
\hline$r_{\text {mer. surf }}$ & $35.22 \pm 6.75$ & $46.31 \pm 5.05$ & $44.66 \pm 5.28$ \\
$r_{\text {zon. surf }}$ & $45.31 \pm 5.12$ & $52.82 \pm 4.95$ & $49.83 \pm 4.22$ \\
$r_{\text {mer. bottom }}$ & $46.11 \pm 5.12$ & $42.33 \pm 5.23$ & $39.11 \pm 5.31$ \\
$r_{\text {zon. bottom }}$ & $46.73 \pm 7.60$ & $42.78 \pm 6.01$ & $42.92 \pm 4.51$ \\
$q_{\text {surf }}$ & $0.83 \pm 0.20$ & $0.90 \pm 0.11$ & $0.93 \pm 0.16$ \\
$q_{\text {bottom }}$ & $1.12 \pm 0.30$ & $1.06 \pm 0.17$ & $0.96 \pm 0.17$ \\
$r_{\text {mer. mean }}$ & $40.85 \pm 4.18$ & $44.30 \pm 4.05$ & $41.88 \pm 4.81$ \\
$r_{\text {zon. mean }}$ & $46.02 \pm 3.70$ & $47.80 \pm 4.59$ & $46.37 \pm 3.78$ \\
$q_{\text {mean }}$ & $0.91 \pm 0.12$ & $0.95 \pm 0.10$ & $0.93 \pm 0.13$ \\
\hline
\end{tabular}

The greatest values of the radii of the concentration region of the spatial correlation function in the salinity field of the surface layer are observed in summer. The indicator $q_{\text {surf }}$ from spring to autumn increases, and $q_{\text {bottom }}$ decreases. Moreover, in spring and summer, zonal water exchange prevails in the surface layer, and meridional water exchange in the bottom layer. The temporal variability nature and the relationship of the studied characteristics can be estimated using graphs presented in Fig. 2-5.

In the surface layer during the first 15 surveys (up to 2006), the zonal radius significantly exceeded the meridional one; later, their values become approximately equal. In the bottom layer, a slight excess of the zonal radius over the meridional one is observed during the first 10 surveys (up to 2004), and during the last 9 surveys (2014-2016) the meridional radius was greater than the zonal one (Fig. 2).

Graphs of the average salinity of the surface and bottom layers (Fig. 4) show that from the spring of 2007 the bottom layer salinity began to exceed noticeably the surface one, and this was observed until the autumn of 2013, when the salinity of the surface and bottom waters became approximately the same.

It can be assumed that the clear predominance of the meridional water transport in the bottom layer ( $q_{\text {bottom }}>1.5$ ) in the surveys carried out in the spring of 2004, 2007 and 2009, in the summer of 2006, 2009 and 2016, in the autumn of 2012 (Fig. $5, a$ ), was determined by the active water inflow from the Kerch Strait. Moreover, the active advection of saline waters was more often manifested in the structure of the salinity field of the bottom layer in spring and summer (during the periods of the highest density stratification of the Sea of Azov waters). 

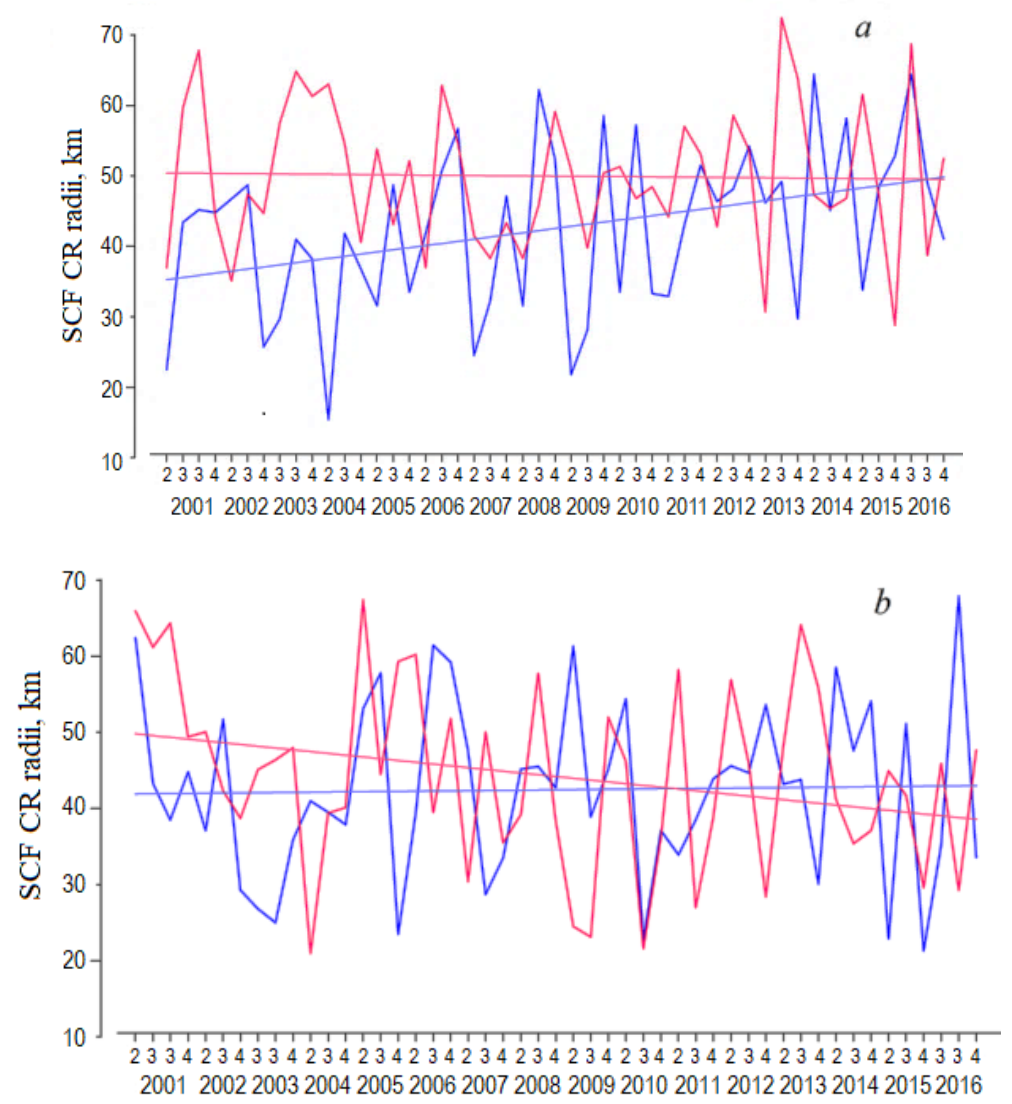

F i g. 2. Changes in the meridional (blue curve) and zonal (red curve) radii of the concentration region of the spatial correlation function on the surface $(a)$ and at the bottom $(b)$, and their linear trends (on the horizontal axis, the seasons of a survey are indicated as: 2 - spring; 3 - summer; 4 - autumn)

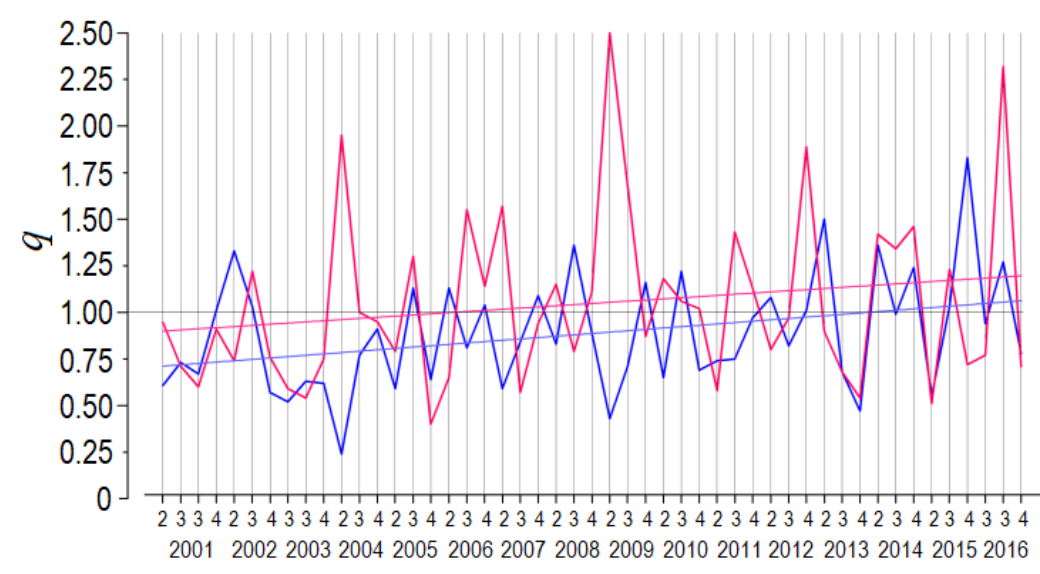

F i g. 3. Changes in the index of the salinity field uniformity $(q)$ on the surface (blue curve) and at the bottom (red curve), as well as their linear trends. See designations in Fig. 2 


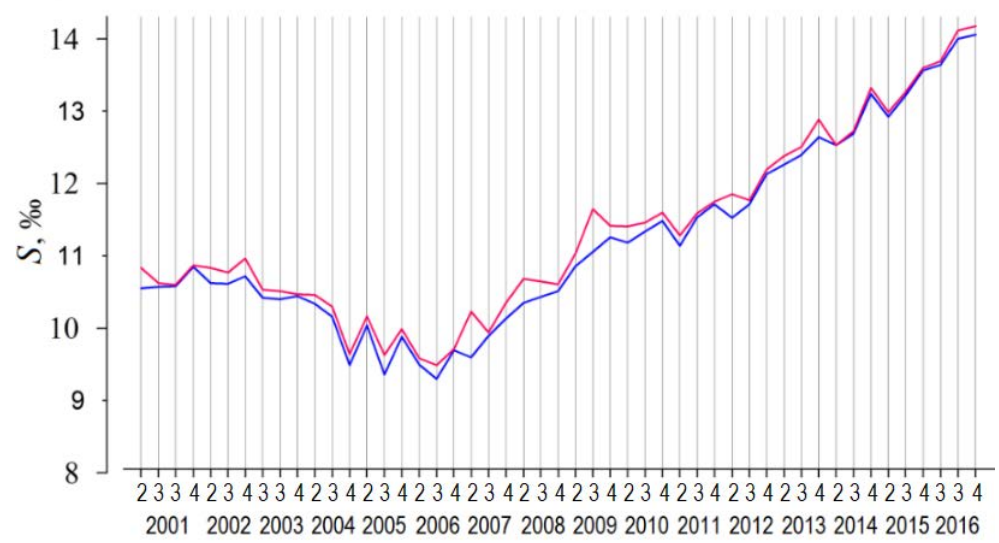

F i g. 4. Average salinity of the surface (blue curve) and bottom (red curve) layers of the Sea of Azov. See designations in Fig. 2
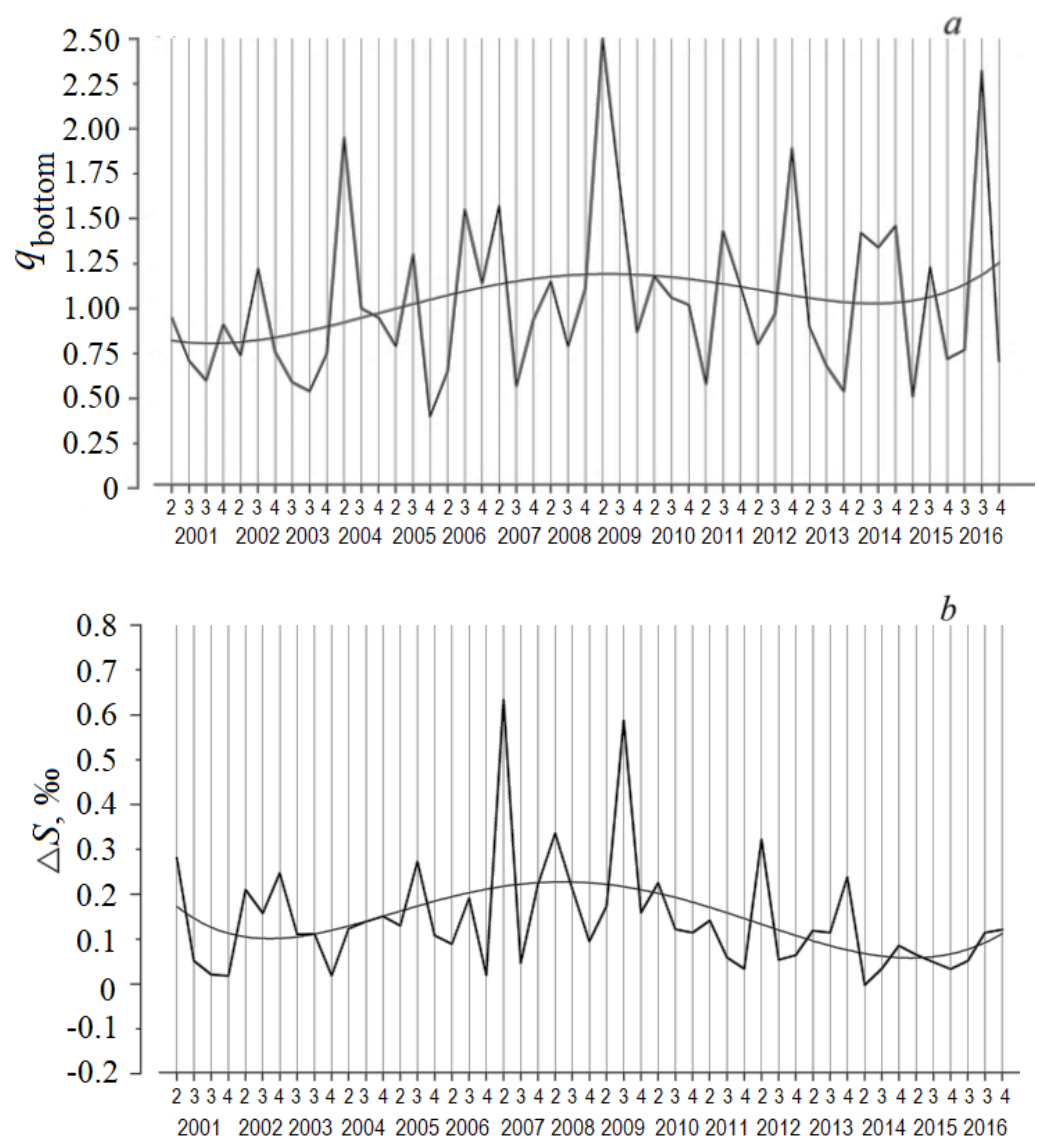

F i g. 5. Changes from surveys of $q_{\text {bottom }}$ indicator ( $a$ ) and difference $(\Delta S)$ between bottom and surface salinity $(b)$ with polynomial smoothing 
This mechanism of the Black Sea water inflow into the Sea of Azov can explain the coincidence of trends (polynomial approximation curves) of changes in the difference in water salinity $(\Delta S)$ in the near-bottom and surface layers (Fig. 5, $b$ ) and the $q_{\text {bottom }}$ indicator (Fig. 5, $a$ ). Activation of the saline waters' inflow in the nearbottom layer during 2005-2012 increased the values of $\Delta S$ and $q_{\text {bottom }}$ (Fig. 5, $a, 5$, b) until the formation of a homohaline vertical structure of waters at an average salinity above 12 \% (see Fig. 4). In 2013-2016 the inflow of the Black Sea waters, apparently, continued, but less actively, without disturbing the vertical haline homogeneity of the waters. These changes were manifested in the tendencies of decreasing the indicators $\Delta S$ and $q_{\text {bottom }}$ in these years. At the end of the study period (summer 2016), a season of a sharp increase in $q_{\text {bottom }}$ was recorded (see Fig. 5, a), which was also reflected in the water salinity increase in the near-bottom layer in this season (see Figs. 4 and 5, $b$ ).

Interestingly, at the extreme points of the polynomial approximations, the $q_{\text {bottom }}$ curve is about three surveys (i.e., a year) ahead of the $\Delta S$ changes.

As an example of the water salinity distribution features in surveys with anomalously high and low values of $q_{\text {mean }}$ (Table 2) during the Sea of Azov desalination (2005) and salinization (2016), Fig. 6 shows the salinity fields in the near-bottom layer, which the difference between $r_{\text {mer }}$ and $r_{\text {zon }}$ is most pronounced in.

T able 2

Indicators of the salinity field structure in the bottom layer of the Sea of Azov waters for the surveys with extreme values of $q_{\text {mean }}$ during the periods of desalination and salinization of sea waters

\begin{tabular}{l|ccccc}
\hline \multicolumn{1}{c|}{ Shooting period } & $r_{\text {mer. bottom }}$ & $r_{\text {zon. bottom }}$ & $q_{\text {bottom }}$ & $q_{\text {mean }}$ \\
\hline July 2005 & 57.8 & 44.5 & 1.30 & 1.23 \\
October 2005 & 23.5 & 59.3 & 0.40 & 0.50 \\
August 2016 & 67.9 & 29.3 & 2.32 & 1.74 \\
October 2016 & 33.6 & 47.6 & 0.71 & 0.76 \\
\hline
\end{tabular}

Main features of these fields are the presence of increased horizontal salinity gradients in the western and eastern parts of the sea in July 2005, the northern and southern - in October 2005, eastern - in August 2016 and southern - in October 2016. It indicates a more active distribution of waters in the near-bottom layer in the meridional direction in summer and in the zonal direction in autumn, which determines the high and low values of the $q$ field, respectively. 

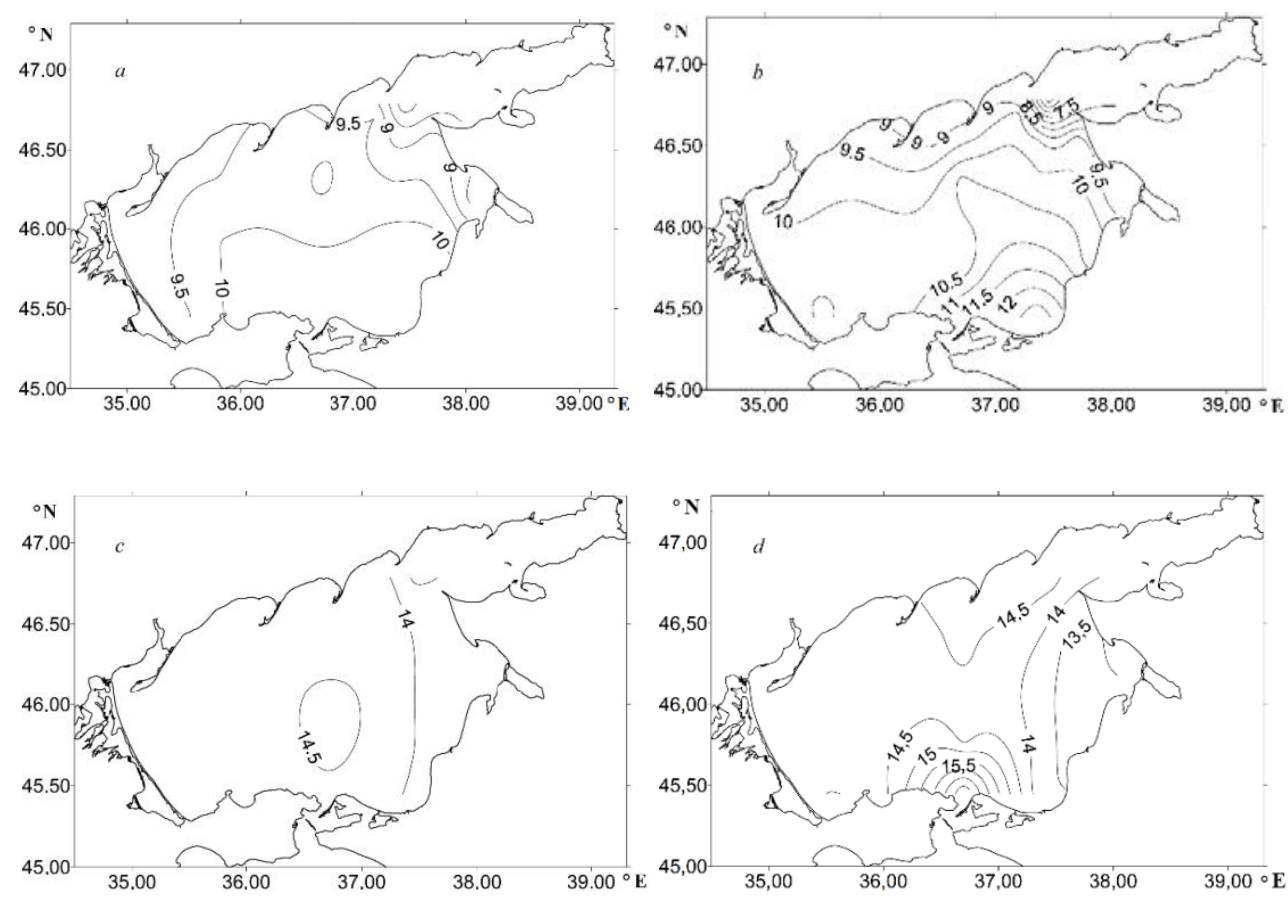

F i g. 6. Salinity fields of the Azov Sea bottom layer from the surveys data with abnormally high and low $q_{\text {mean }}$ values during desalination: July (a), October (b), 2005 and salinization: August (c), October (d), 2016

Dependence of the sea salinity increase on the meridional water exchange activation is confirmed by the results of the paired linear correlation analysis of the studied seasonal characteristics of the salinity field (Table 3). This analysis made it possible to reveal statistically significant relationships between the structural characteristics ( $r_{\text {mer. surf. }} q_{\text {surf }}$ and $q_{\text {mean }}$ ) with the average salinity values of the Sea of Azov within the seasonal variability framework.

T a ble 3

Correlation coefficients (with correlation reliability $\geq 0.95$ ) of the characteristics of the Azov Sea salinity field based on 48 surveys in 2001-2016

\begin{tabular}{l|c|c|c}
\hline \multicolumn{1}{c|}{ Characteristics } & $S_{\mathrm{Az}}$ & $S_{\text {surf }}$ & $S_{\text {bottom }}$ \\
\hline$r_{\text {mer. surf }}$ & 0.32 & 0.33 & 0.30 \\
$q_{\text {surf }}$ & 0.29 & 0.29 & 0.28 \\
$q_{\text {mean }}$ & 0.31 & 0.30 & 0.31 \\
\hline
\end{tabular}


Correlation coefficients (with correlation reliability $\geq 0.95$ ) of the average annual characteristics of the Azov Sea salinity field in 2001-2016

\begin{tabular}{l|c|c|c}
\hline \multicolumn{1}{c}{ Characteristics } & $S_{\mathrm{Az}}$ & $S_{\text {surf }}$ & $S_{\text {bottom }}$ \\
\hline \multicolumn{4}{c}{0 Shift } \\
\hline$r_{\text {mer. surf }}$ & 0.56 & 0.56 & 0.55 \\
$q_{\text {surf }}$ & 0.55 & 0.55 & 0.55 \\
$q_{\text {mean }}$ & 0.51 & 0.50 & 0.50 \\
\hline \multicolumn{4}{c}{1 -year shift } \\
\hline$r_{\text {mer. surf }}$ & 0.57 & 0.56 & 0.58 \\
$q_{\text {surf }}$ & 0.66 & 0.65 & 0.67 \\
$q_{\text {mean }}$ & 0.50 & 0.51 & 0.52 \\
\hline \multicolumn{5}{r}{$r_{\text {mer. surf }}$} & 2 -year shift & 0.65 \\
$q_{\text {surf }}$ & 0.65 & 0.65 & 0.62 \\
$q_{\text {mean }}$ & 0.61 & 0.61 & 0.58 \\
\hline \multicolumn{5}{l}{$r_{\text {mer. surf }}$} & 0.59 & 0.58 & 0.48 \\
$q_{\text {surf }}$ & 3 -year shift & - \\
$q_{\text {mean }}$ & 0.49 & 0.49 & - \\
\hline
\end{tabular}

The results of the paired linear correlation of the average annual values of the studied characteristics of the salinity field (Table 4) indicate their closest relationship with the structural characteristics with the anticipatory shift of the structural indicators by 1 and 2 years relative to the average water salinity values, which makes it possible to use these relationships in predicting the average sea salinity with a lead time of up to two years.

Consequently, the water salinity increase within the framework of seasonal and interannual variability is associated with the meridional water exchange activation in the sea (primarily in the surface layer) and the weakening of the zonal water exchange, which ensured after 2006 the water inflow intensification into the Sea of Azov from the Kerch Strait.

Conclusions. From 2001 to 2016, the average values of the meridional and zonal the radii of the concentration region of the spatial correlation function (42.5 and $47.1 \mathrm{~km}$ ) were relatively close with some predominance of the zonal component and indicated the presence of two relatively isolated zones in the sea, associated with water circulation. In the near-bottom layer, the average values of the zonal and meridional radii were also approximately equal, in the surface layer, the zonal radii exceeded the meridional ones, which indicates the river runoff influence.

In spring and summer, the zonal radius in the surface water layer was larger, and the meridional radius in the bottom layer, indicating an increase in the water exchange influence with the Taganrog Bay in the surface layer in these seasons and with the Kerch Strait in the bottom layer. Trends of long-term changes in the radii of the concentration region of the spatial correlation function of the salinity field 
demonstrate an increase in the meridional radius in the surface layer, and a decrease in the zonal radius in the bottom layer.

Changes in the salinity field structure (with trends of a decrease in the radii of the concentration region of the spatial correlation function and an increase in the meridional radii) are associated with an increase in the average salinity of sea waters after 2006 and, probably, are a consequence of a decrease in the river water inflow and an increase in water exchange in the Sea of Azov water area with the Kerch Strait.

Close relationship between the average annual values of the structural indices of the salinity field with their anticipatory shift by 1 and 2 years relative to the values of the mean salinity of sea waters makes it possible to use these relationships in predicting the average sea salinity with a lead time of up to two years.

\section{REFERENCE}

1. Berdnikov, S.V., Dashkevich, L.V. and Kulygin, V.V., 2019. Climatic Conditions and Hydrological Regime of the Sea of Azov in the XX - Early XXI Centuries. Aquatic Bioresources \& Environment, 2(2), pp. 7-19 (in Russian).

2. Drozdov, V.V., 2010. Features of Long-Term Dynamics of an Ecosystem of Sea of Azov under the Influence of Climatic and Anthropogenous Factors. In: RSHU, 2010. Uchenyye Zapiski RGGMU [Scientific Notes of the Russian State Hydrometeorological University]. Saint Petersburg: RSHU Publ. Issue 15, pp. 155-176 (in Russian).

3. Bronfman, A.M. and Khlebnikov, E.P., 1985. [The Sea of Azov. Fundamentals of Reconstruction]. Leningrad: Gidrometeoizdat, 270 p. (in Russian).

4. Bronfman, A.M., Dubinina, V.G. and Makarova, G.D., 1979. [Hydrological and Hydrochemical Foundations of the Productivity of the Sea of Azov]. Moscow: Pishchevaya promyshlennost, 288 p. (in Russian).

5. Matishov, G.G., Gargopa, Yu.M., Berdnikov, S.V. and Dzhenyuk, S.L., 2006. [Regularities of Ecosystem Processes in the Sea of Azov]. Moscow: Nauka, 304 p. (in Russian).

6. Kochergin, A.T., Zhukova, S.V. and Malygin, Ye.Yu., 2018. Inter-Annual Variability of Salinity and Vertical Thermohaline Stability in the Different Areas of the Sea of Azov in Summer Season of 1992-2016. Monitoring Systems of Environment, 11, pp. $63-68$ (in Russian).

7. Il'in, Yu.P., Fomin, V.V., D'yakov, N.N. and Gorbach, S.B., 2009. [Hydrometeorological Conditions of the Seas of Ukraine. Vol. 1. The Sea of Azov]. Sevastopol, 401 p. (in Russian).

8. Diyakov, N.N., Gorbach, S.B., Fomin, V.V. and Ilyin, Yu.P., 2006. Modern Thermohaline Structure of the Sea of Azov Waters. In: MHI, 2006. Ekologicheskaya Bezopasnost' Pribrezhnykh i Shel'fovykh Zon i Kompleksnoe Ispol'zovanie Resursov Shel'fa [Ecological Safety of Coastal and Shelf Zones and Comprehensive Use of Shelf Resources]. Sevastopol: ECOSI-Gidrofizika. Iss. 14, pp. 215-224 (in Russian).

9. Cherkesov, L.V. and Shul'ga, T.Ya., 2017. [Waves, Currents, Surge Processes and Transformation of Pollution in the Sea of Azov]. Sevastopol: MHI, 228 p. (in Russian).

10. Berdnikov, S.V., Kleshchenkov, A.V., Grigorenko, K.S., Oleinikov, E.P., Moskovets, A.Yu., Dashkevich, L.V., Kulygin, V.V., Sorokina, V.V. and Soier, V.G., 2019. Results of Marine Scientific Research of the Southern Scientific Center of the Russian Academy of Sciences. Aquatic Bioresources \& Environment, 2(3), pp. 7-19 (in Russian).

11. Kosarev, A.N., Kostianoy, A.G. and Shiganova, T.A., 2008. The Sea of Azov. In: A. G. Kostianoy, A. N. Kosarev, Eds., 2007. The Black Sea Environment. The Handbook of Environmental Chemistry, vol. 5Q. Berlin: Springer, pp. 63-89. doi:10.1007/698_5_091

12. Matishov, G., Matishov, D., Gargopa, Yu., Dashkevich, L., Berdnikov, S., Baranova, O. and Smolyar, I., 2006. Climatic Atlas of the Sea of Azov 2006. NOAA Atlas NESDIS 59. Washington, DC: U.S. Government Printing Office, 2006. 103 p. Available at: https://www.nodc.noaa.gov/OC5/AZOV2006/start.html [Accessed: 05 June 2021]. 
13. Panov, B.N. and Spiridonova, E.O., 2007. Some Regularities of Salinity Field Formation in the Sea of Azov. In: MHI, 2007. Ekologicheskaya Bezopasnost' Pribrezhnykh i Shel'fovykh Zon i Kompleksnoe Ispol'zovanie Resursov Shel'fa [Ecological Safety of Coastal and Shelf Zones and Comprehensive Use of Shelf Resources]. Sevastopol: ECOSI-Gidrofizika. Iss. 15, pp. 152158 (in Russian).

14. Glukhovskoy, B.Kh., Ed., 1986. [Hydrometeorological Conditions of the Shelf Zone of the Seas of the USSR. Vol. 3. Sea of Azov]. Leningrad: Gidrometeoizdat, 217 p. (in Russian).

15. Andryushchenko, A.A. and Belyaev, V.I., 1972. A Study of the Statistical Structure of Black Sea Temperature Fields and Salinity in Application to the Problem of Their Objective Analysis. Izvestiya Akademii Nauk SSSR Fizika Atmosfery i Okeana, 8(9), pp. 1004-1008 (in Russian).

16. Andryushchenko, A.A. and Belyaev, V.I., 1978. [Mathematical Support for Calculations of Oceanographic Fields Based on Observational Data]. Kiev: Naukova dumka, 134 p. (in Russian).

About the authors:

Elena O. Spiridonova, Assistant Professor, FSBEI HE Kerch State Marine Technological University (KSMTU) (82 Ordzhonikidze St., Kerch, 298309, Russian Federation), Ph. D. (Geogr.), ORCID ID: 0000-0003-1029-6565, Author ID: 949714, Scopus Author ID: 6603687318, helena.spyrydonova@gmail.com

Boris N. Panov, Leading Research Associate, 2 Azov-Black Sea Branch ("AzNIIRKH") of FGBNU "VNIRO" (21v Beregovaya St., Rostov-on-Don, 344002, Russian Federation), Assistant Professor, FSBEI HE Kerch State Marine Technological University (KSMTU) (82 Ordzhonikidze St., Kerch, 298309, Russian Federation), Ph. D. (Geogr.), Leading Research Associate, ORCID ID: 00000001-6875-8713, Author ID: 855131, Scopus Author ID: 6701762844, panov_bn@mail.ru

Contribution of the co-authors:

Elena O. Spiridonova - significant participation in design, idea presentation, leadership, article writing

Boris N. Panov - significant participation in design, idea presentation, leadership, article writing

All the authors have read and approved the final manuscript.

The authors declare that they have no conflict of interest. 